American Journal of Applied Sciences 5 (5): 597-604, 2008

ISSN 1546-9239

(C) 2008 Science Publications

\title{
Pile Instrumentation Using Retrievable Sensors
}

\author{
${ }^{1}$ Faisal Hj. Ali, ${ }^{2}$ Bujang B.K. Huat and ${ }^{3}$ Lee, Sieng Kai \\ ${ }^{1}$ Department of Civil Engineering, University of Malaya, 50603 Kuala Lumpur \\ ${ }^{2}$ Department of Civil Engineering, University Putra Malaysia, 43400 Serdang \\ ${ }^{3}$ Glostrext Technology Sdn. Bhd., No.38-40, Jalan Desa Serdang, \\ 43300 Serdang Lama, Selangor, Malaysia
}

\begin{abstract}
Strain gauges are normally used to monitor the shortening or compression of pile during static pile load test. For concrete spun pile, the technique used either by incorporating high temperature-resistant strain gauges into the heat-cured production process of the spun piles or by installing an instrumented steel pipe into the hollow core of the spun piles followed by cement grout infilling. The former is extremely unpopular due to high cost of these gauges and the uncertainty over their ability to survive the pile production and driving processes. The shortcoming of the other technique is the infilling of cement grout substantially alters the structural properties of the piles, thus rendering their load-response behaviour significantly different from that of the actual working piles. To address the difficulties of the above techniques a new method was recently developed by the authors, which uses retrieval sensors instead of strain gauges (which have to be sacrificed in every test). The method also has the ability to monitor loads and displacements at various levels along the pile shaft and toe of instrumented piles. Results of field tests show high quality, reliable and consistent data, clearly far exceeding the capability of both conventional and approximate methods of using strain gauges.
\end{abstract}

Key words: pile, strain gauge, cement grout

\section{INTRODUCTION}

The high strength prestressed spun concrete piles, commonly driven with hydraulic impact hammers or preferably installed with jacked-in rigs when considering the stricter regulations with respect to noise and vibrations in more urban areas, often offer a competitive choice of foundation system for projects with medium and high loadings. They are widely used in foundations for schools, high-rise buildings, factories, ports, bridges and power plants in this region.

In early years, the main construction control for driven piles was mostly based on the measurement of set of each pile coupled with a selected small number of non-instrumented static load tests to verify the specified load-settlement requirements.

In recent years, with critical evolution in the understanding of the load transfer and bearing behaviour of piles (mainly through analysis of instrumented full-scale load tests), many engineers can now appreciate that the pile performance is not simply a matter of ultimate load value alone $e^{[1,2]}$. According to Fleming ${ }^{[3]}$ some of the basic parameters required for forecasting pile deformation under loads include (a) Ultimate shaft load and its characteristics of transformation to the ground; (b) Ultimate base load; (c) Stiffness of the soil below the pile base; (d) Pile dimensions; and (e) Stiffness of the pile material.

Conventional instrumentation method: A conventional instrumentation scheme for spun pile static load testing is shown in Fig. 1. The method involves incorporating high temperature-resistant strain gauges into the heat-cured production process of prestressed spun concrete piles.

This method is extremely unpopular and difficult to be routinely applied in project sites due to the following constraints:

- High cost of these temperature-resistant strain gauges;

- Tremendous difficulties involved in coordinating the installation of the strain gauges into pile segments;

Corresponding Author: $\quad$ Bujang B.K. Huat, PhD, DIC, Engr., Professor, Department of Civil Engineering, Faculty of Engineering, University Putra Malaysia 43400 UPM, Serdang. Selangor. MALAYSIA 
Am. J. Applied Sci., 5 (5): 597-604, 2008

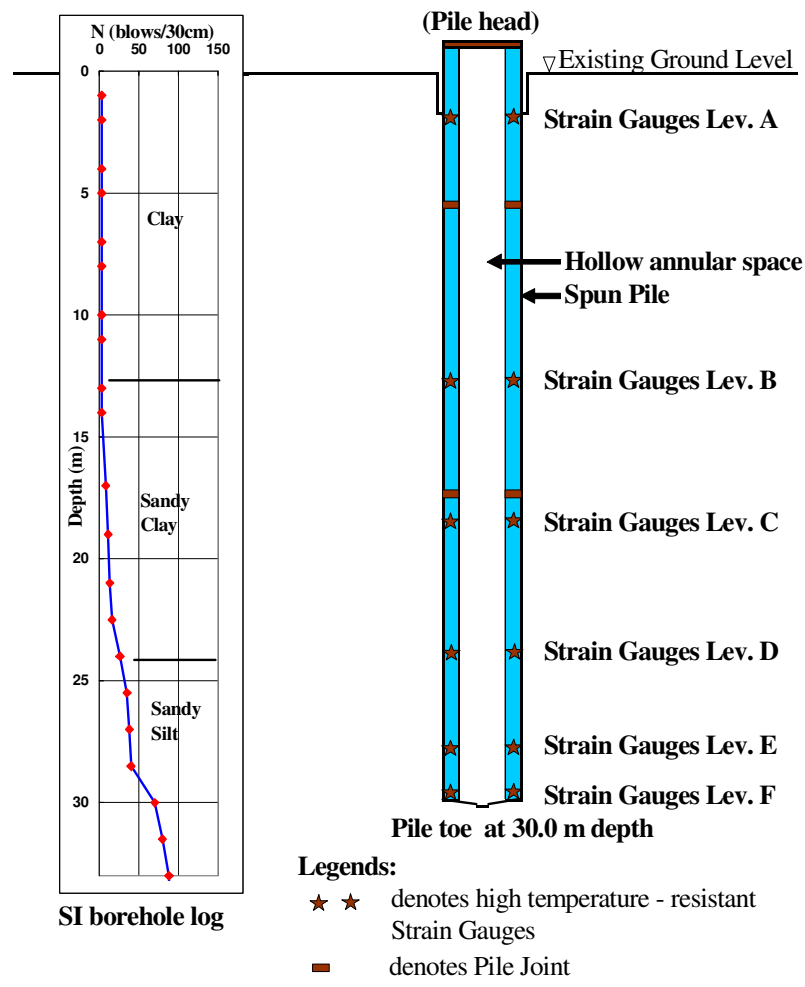

Fig. 1: Diagrammatic illustration of conventional spun pile instrumentation scheme

- Long lead-time is normally required for instrumentation works, as the instruments have to be pre-assembled and installed onto the high strength prestressing bar cage prior to heat-cured spin-cast production process of the piles; and

- Great uncertainty over the ability of the delicate instruments to withstand the stresses arising from pile production and driving processes.

Approximate instrumentation method: Due to the difficulties of using the conventional method, the engineering community for spun pile industry has been using an approximate instrumentation method for the past few decades, by installing either an instrumented reinforcement cage or an instrumented pipe, into the hollow core of spun piles followed by cement grout infilling (Fig. 2).

Figure 3 shows typical sequence of spun pile installation by jack-in method, commonly used vibrating wire strain gauges mounted to steel pipe, lowering of instrumented pipe into the annular space of the test pile followed by cement grout infilling.

As this approximate method is comparatively more convenient to be implemented than the conventional

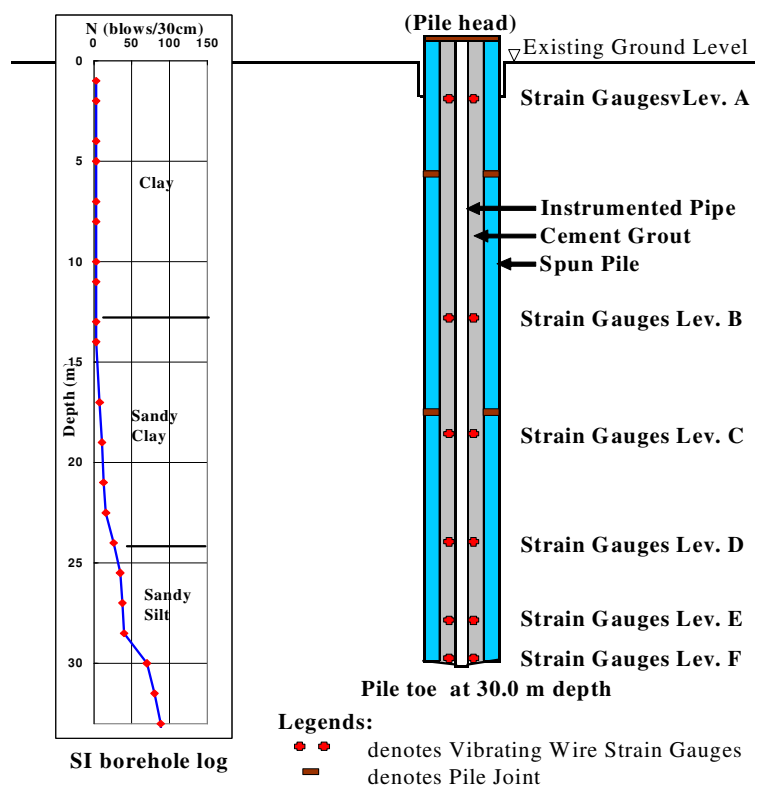

Fig. 2: Diagrammatic illustration of approximate spun pile instrumentation method

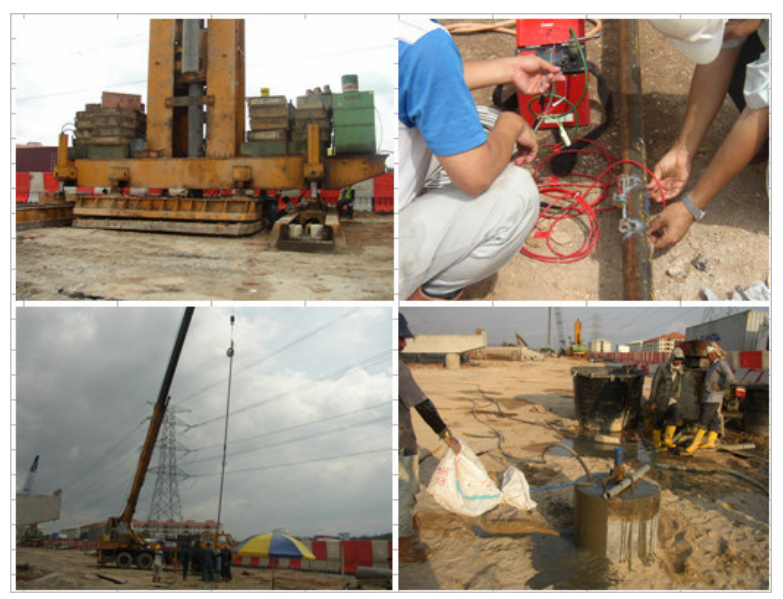

Fig. 3: Typical installation process of spun pile instrumentation in approximate method

method, it was widely practiced in this region for the past few decades.

Some contract specifications also ask for the inclusion of conventional sleeved rod extensometers (depending on the space available) to monitor the pile shortening reading during the static load tests. Either using an instrumented reinforcement cage or an instrumented pipe, with or without the added-in sleeved rod extensometers, the end product after the cement grout infilling is more towards a solid pile.

Therefore the obvious shortcomings of this approximate method include: 
- The infilling of cement grout substantially alters the structural properties of the piles, thus rendering them significantly different from the actual working spun piles, which are usually not grouted internally;

- The change in strain in the post-grouted core under the applied loading may not be the same as the change in strain in the prestressed concrete wall of the pile because of the different stiffness of the two materials of different mix, strength and age;

- Structural shortening measurement of the test piles are not representative of the actual working piles;

- Structural integrity of the original pile cannot be reliably ascertained, particularly performance of pile joints, during the static load test; and

- Significant time loss due to grout infilling and curing process, beside the environmental unfriendly nature of this method.

\section{DEVELOPMENT OF A NEW INSTRUMENTATION METHOD}

To address the challenges and difficulties posed by the conventional and approximate methods, retrieval sensors hereby named as global strain extensometers for spun piles had been developed, improved and field tested, by the authors.

Description of the Global Strain Extensometer: The technology consists of a deformation monitoring system that uses advanced pneumatically- or hydraulicallyanchored extensometers coupled with high-precision spring-loaded transducers, and a novel analytical technique to monitor loads and displacements down the shaft and at the toe of foundation piles. This method is particularly useful for monitoring pile performance and optimizing pile foundation design.

To appreciate the innovation contained in the technology, the basic deformation measurement in the pile by strain gauges and tell-tale extensometers are reviewed. Normally, strain gauges (typically short gauge length) are used for strain measurement at a particular level or spot, while tell-tale extensometers (typically long sleeved rod length) are used purely for shortening measurement over an interval (over a length between two levels). From a strain measurement point of view, the strain gauge gives strain measurement over a very short gauge length while the tell-tale extensometer gives strain measurement over a very long gauge
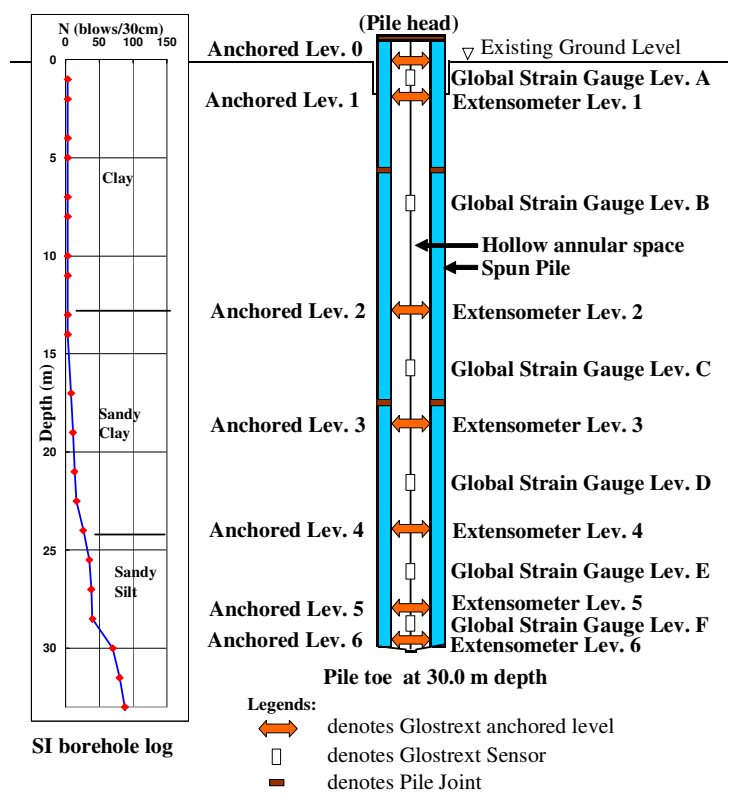

Fig. 4: Schematic diagram of typical instrumented spun pile using global strain extensometer technology

length. Tell-tale extensometer that measure strain over a very long gauge length may be viewed as a very large strain gauge or simply called global strain extensometer. With recent advancement in the manufacturing of highprecision spring-loaded vibrating-wire sensors, it is now possible to measure strain deformation over the entire length of piles in segments with ease during static load testing.

Figure 4 shows a schematic spun pile instrumentation diagram using the global strain extensometer. This system is equivalent to the conventional method of using 24 no. strain gauges and 6 no. sleeved rod extensometers, which might not be possible to be installed satisfactorily due to congestion in the spun piles.

For the analysis of test data for spun piles using the global strain extensometer, the load distribution can be computed from the measured changes in global strain gauge readings and pile properties (cross-section area of spun pile and concrete modulus). Load transferred $\left(\mathrm{P}_{\text {Ave }}\right)$ at mid-point of each anchored interval can be calculated as:

$$
\mathrm{P}=\varepsilon\left(\mathrm{E}_{\mathrm{c}} \mathrm{A}_{\mathrm{c}}\right)
$$

Where:

$\varepsilon=$ Average change in global strain gauge readings;

$\mathrm{A}_{\mathrm{c}}=$ Cross-sectional area of spun pile section;

$\mathrm{E}_{\mathrm{c}}=$ Concrete secant modulus in pile section. 
With the instrumentation set-up as described in Figure 4, the global strain extensometers system is able to measure shortening and strains over an entire section of the test pile during each loading steps of a typical static pile load test, thus it integrates the strain over a larger and more representative sample.

Advantages of Using the Global Strain Extensometer: Due to the significant difference in the methodology evolution, from conventional sacrificial cast-in method to a new retrievable post-install approach, the global strain extensometer technology has been proven via a large number of full-scale load tests to be a reliable and powerful pile load testing and data interpretation tool.

Some of the obvious benefits of using global strain extensometer technology are as follow:

- The technology enables installation of instrumentation after pile-driving and thus virtually eliminates the risk of instrument damage during pile production and installation;

- The post-install nature of the method empowers engineers to select instrumentation levels along the as-built depth of foundation piles using pile driving/installation records and site investigation data as guides;

- The technology reliably measures segmental shortening/elongation and strain over an entire section of the test pile during each loading step of a typical static load test. Unlike the conventional strain gauges that make just localized strain measurements, the new technology integrates individual measurements over a larger and more representative sample;

- Significant cost and time saving, as the additional cage and cement grout infilling are not required;

- The technology is extremely environmental friendly, as the sensors are retrievable, and no messing around with cement grouts; and

- Mass implementation of spun piles instrumentation is now made viable with this technology, to capture representative and reliable data in large quantities to assist engineers to build up a reliable databank for better design and safety.

\section{FIELD TESTS RESULTS AND DISCUSSION}

The technology has been recently used to fully instrument a $500 \mathrm{~mm}$ diameter (with $90 \mathrm{~mm}$ wall thickness) jacked in prestressed spun concrete pile for a

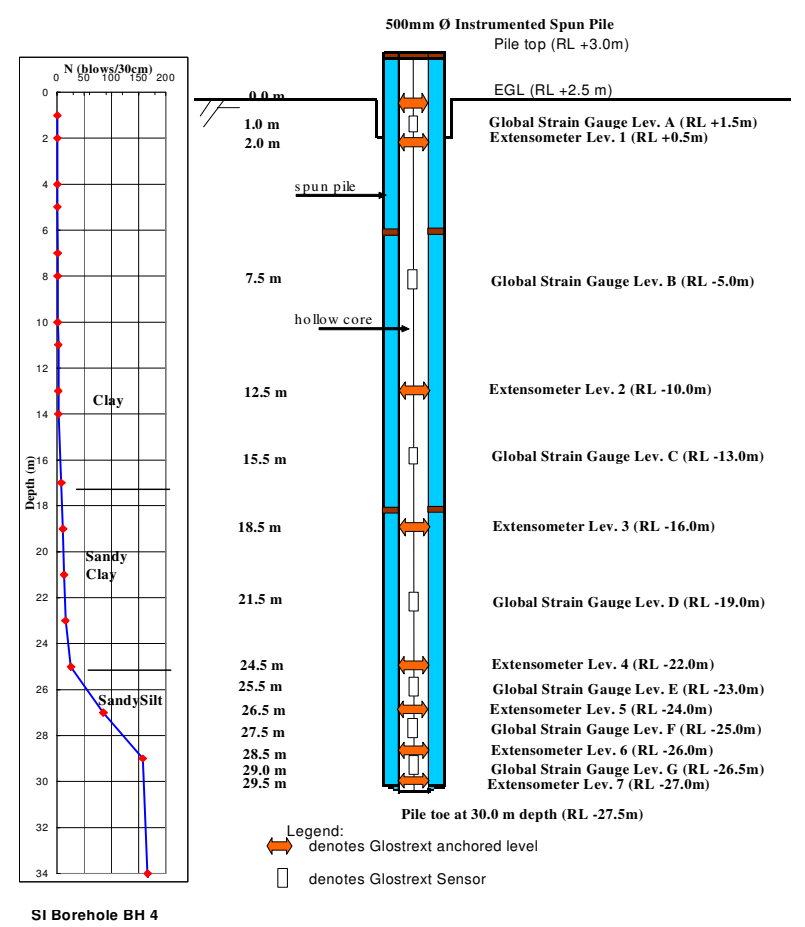

Fig. 5: Test Pile (TP1) instrumentation using global strain extensometer at Melaka site, Malaysia

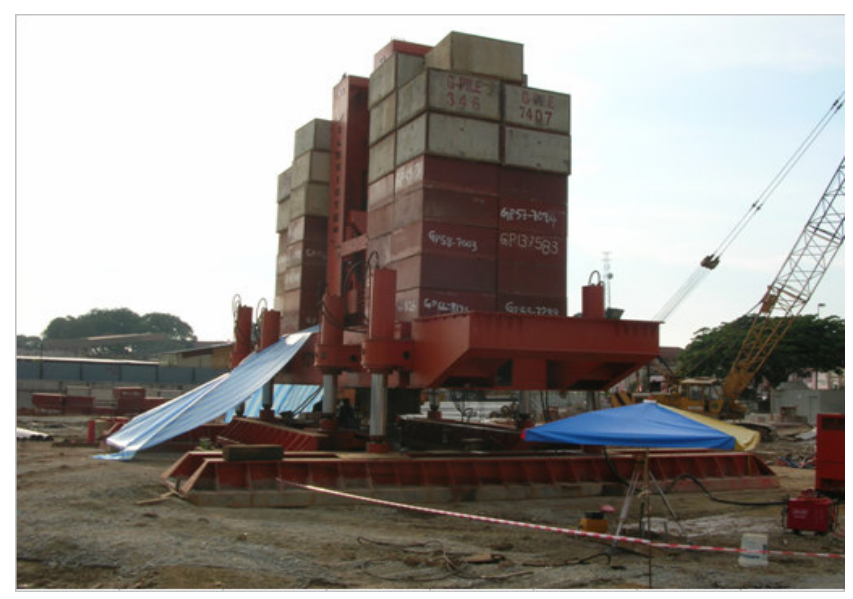

Fig. 6: Static axial compression load test set-up for TP1 at Melaka site, Malaysia

commercial building project in the state of Melaka, Malaysia. The test pile (TP1) instrumentation details along with nearby borehole SPT N-values plot are graphically represented in Fig. 5. The pile was jacked-in to $30 \mathrm{~m}$ penetration length when the jack-in force reached approximately two times working load or $4000 \mathrm{kN}$. The jack-in frame was also used for subsequent static load test (Fig. 6). 


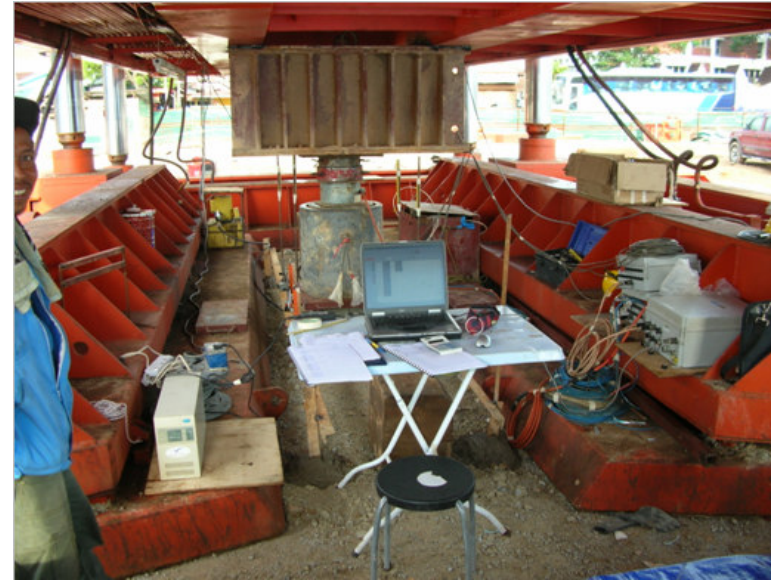

Fig. 7: Instrumentation and monitoring test set-up for TP1 at Melaka site, Malaysia

Pile head movement was monitored using both Linear Variation Displacement Transducers (LVDTs) and by affixing pile tops with vertical scale rules that could then be sighted by precise level instruments. Vertical scales were similarly provided on the reference frame to monitor frame movements during load testing. The applied loads were measured by calibrated vibrating-wire load cell. The vibrating-wire load cell, global strain extensometers and LVDTs were all logged automatically using a Micro-10x datalogger system (Fig. 7).

Pile head settlement and pile settlement at various depths including pile toe (derived by subtracting the structural shortening at corresponding depth from the pile head settlement) are presented in Fig. 8.

In the pile test analysis, it is highly recommended in practical terms to obtain the pile concrete modulus, $E_{c}$ value directly from the material of the pile ${ }^{[4]}$. Global strain extensometer technology appeared to provide an excellent answer to this recommendation (Fig. 9), giving a reliable site-specific calibration of straindependent modulus to be ascertained before converting strains into axial loads.

A conspicuous benefit which can be derived from the plots shown in Fig. 8 and 9 is that they enable engineers and researchers nowadays to have an opportunity to have an insight understanding on the relationship between the pile settlement along the pile depth and the corresponding load transfer characteristics.

The new instrumentation technique was also used in the pre-production pile testing program for the US\$ 800 million 1400 MW Coal Fired Jimah Power Plant Project in Negeri Sembilan, Malaysia. The pile
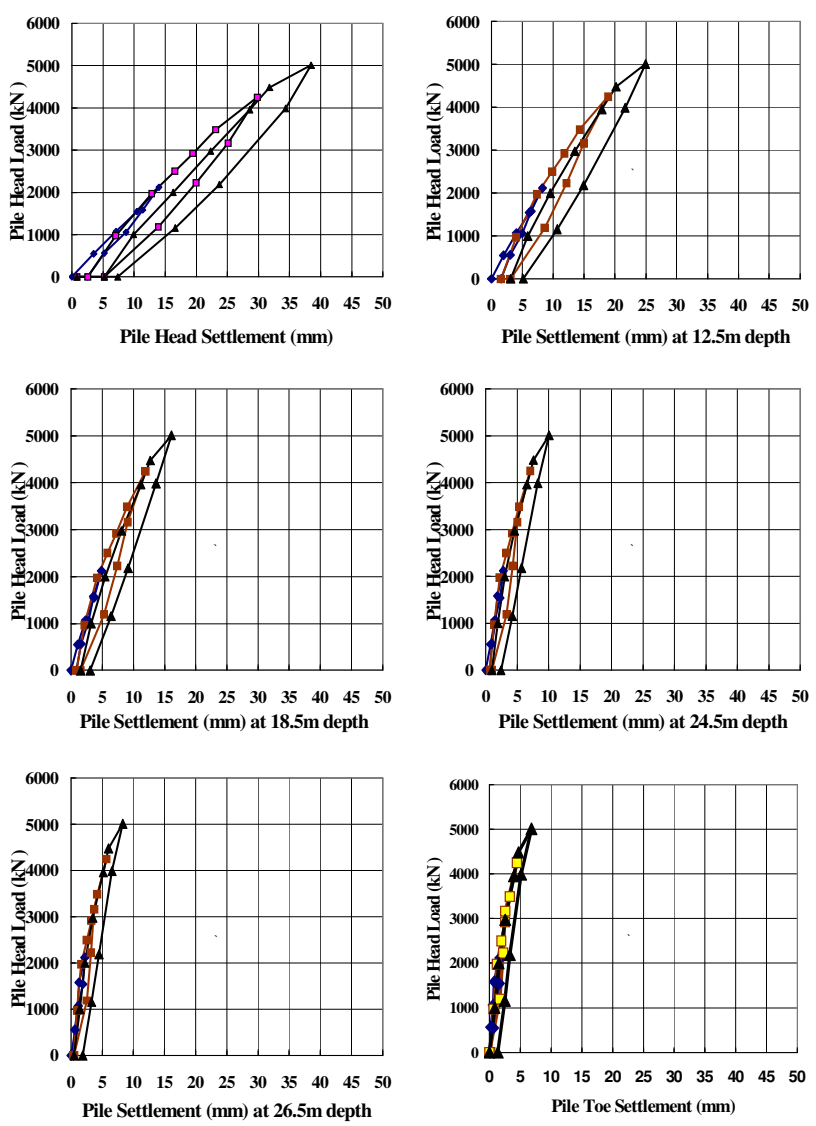

Fig. 8: Pile head settlement and pile settlement at various depths including pile toe for TP1 at Melaka site, Malaysia

Table 1: Prestressed Spun Concrete Pile Properties

\begin{tabular}{lllll}
\hline $\begin{array}{l}\text { Test } \\
\text { Pile }\end{array}$ & $\begin{array}{l}\text { Nominal } \\
\text { Diameter } \\
(\mathrm{mm})\end{array}$ & $\begin{array}{l}\text { Wall } \\
\text { Thickness } \\
(\mathrm{mm})\end{array}$ & $\begin{array}{l}\text { Pile } \\
\text { Length } \\
(\mathrm{m})\end{array}$ & $\begin{array}{l}\text { Prestressing } \\
\text { Bar } \\
(9 \mathrm{~mm} \emptyset)\end{array}$ \\
\hline TP3C & 600 & 100 & 38.9 & 14 no. \\
TP5 & 500 & 90 & 38.1 & 10 no. \\
TP6 & 500 & 90 & 17.5 & 10 no. \\
TP7 & 500 & 90 & 17.5 & 15 no. \\
TP9 & 400 & 80 & 41.7 & 8 no. \\
\hline
\end{tabular}

instrumentation schemes adopted for the pre-production spun pile testing programme are graphically represented in Fig. 10 and 11. The pre-production prestressed spun concrete piles TP3C was installed with an 11-ton BSP hydraulic impact hammer while piles TP5, TP6, TP7 and TP9 were installed with a 9-ton Junttan hydraulic impact hammer. Preboring was carried out over the upper $12 \mathrm{~m}$ for piles TP3C and TP5. The structural properties of these driven prestressed spun concrete piles are summarized in Table 1. 

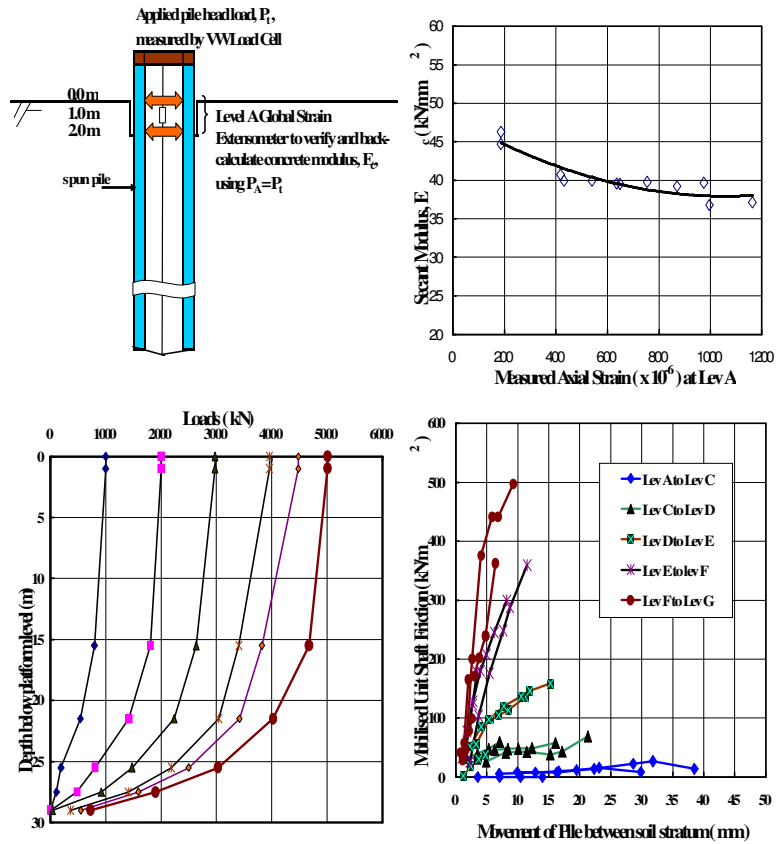

Fig. 9: Level A sensor arrangement for verifying and back-calculate $E_{c}$ values, modulus-strain curve, load distribution curve and mobilized unit shaft friction versus average movement of pile between soil stratum measured using global strain extensometer for TP1

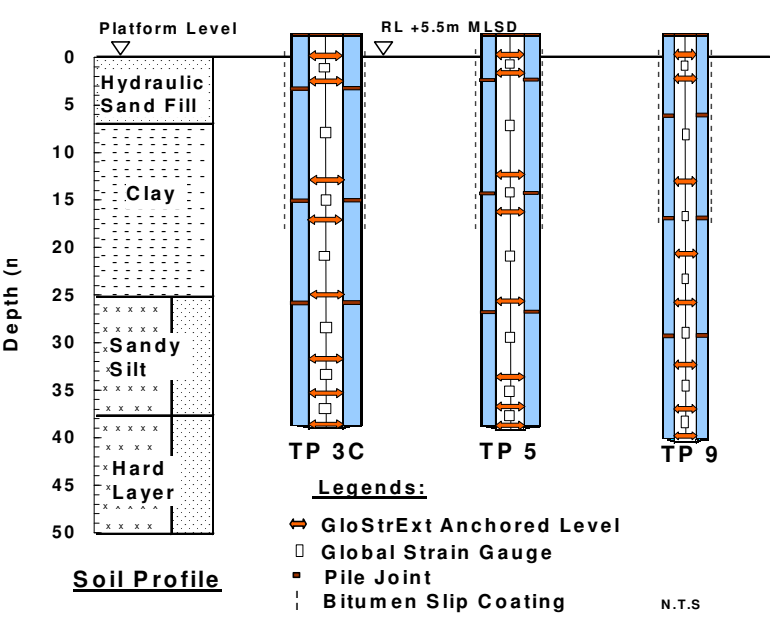

Fig. 10: Schematic diagram of instrumentation details for static axial compression load tests on spun piles using global strain extensometer technology at Jimah site, Malaysia

The test results acquired from global strain extensometer technology on all tested piles appeared to be consistent, and the test results for the two tension test piles TP6 and TP7 are reproduced here to highlight

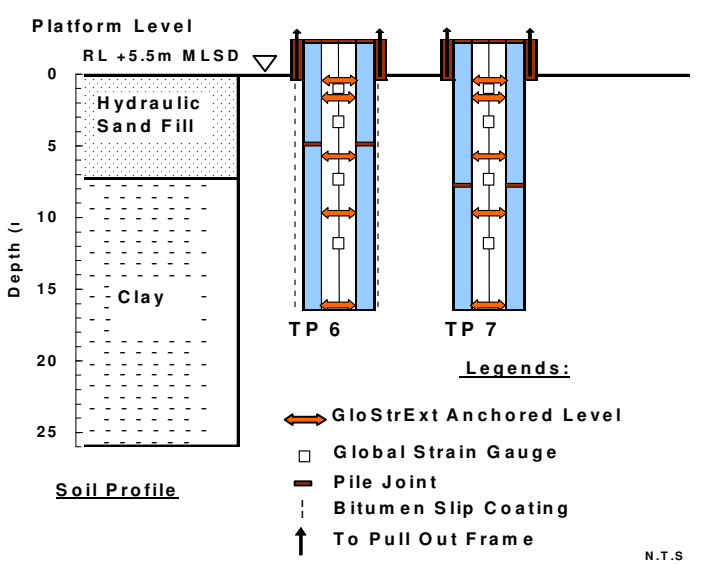

Fig. 11: Schematic diagram of instrumentation details for static axial tension load tests on spun piles using global strain extensometer technology at Jimah site, Malaysia

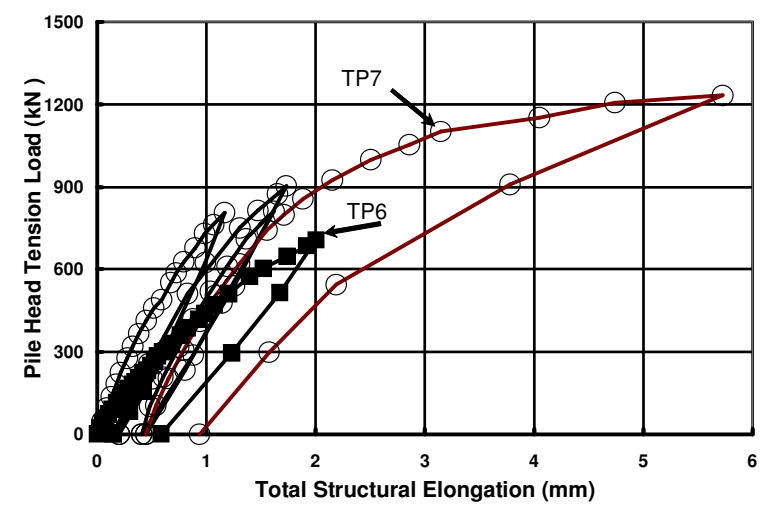

Fig. 12: Pile head tension load versus total structural elongation for TP6 and TP7 measured using global strain extensometer technology at Jimah site, Malaysia

the capability of this technology. From highly consistent measurements of the structural elongation of the entire length of piles TP6 and TP7 using global strain extensometers (Fig. 12), the pile toe upward displacement behaviors (Fig. 13) can be reliably established by subtracting the structural elongation from the pile head upward displacement (Fig. 14).

Similarly, global strain extensometer technology also enable pile displacement under load at any depth along the shaft to be accurately derived, based on its ability to make segmental or global shortening/elongation measurement along the whole pile independent of any external reference and free of common errors associated with the conventional sleeved rod extensometers. This enables the movement 


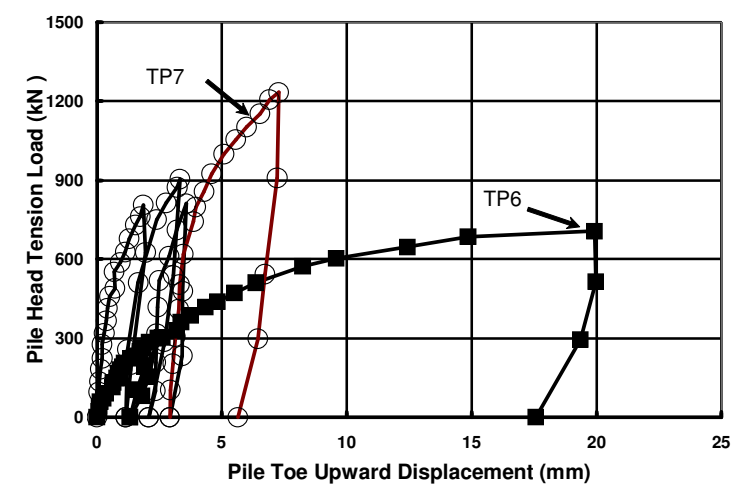

Fig. 13: Pile head tension load versus pile toe upward displacement for TP6 and TP7 at Jimah site, Malaysia

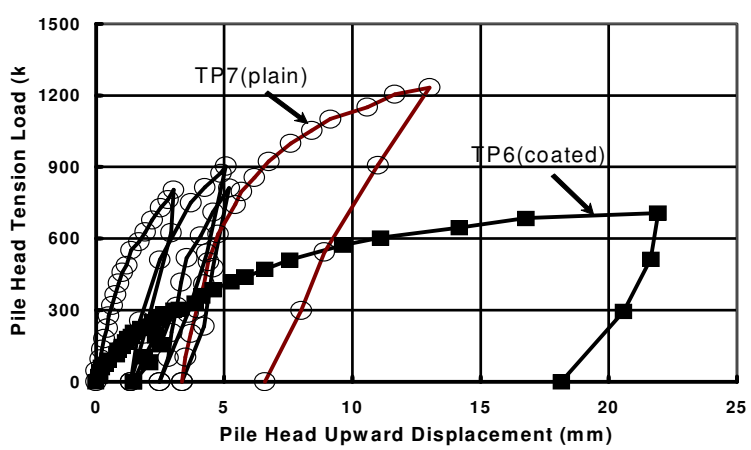

Fig. 14: Pile head tension load versus pile head upward displacement for TP6 and TP7 at Jimah site, Malaysia
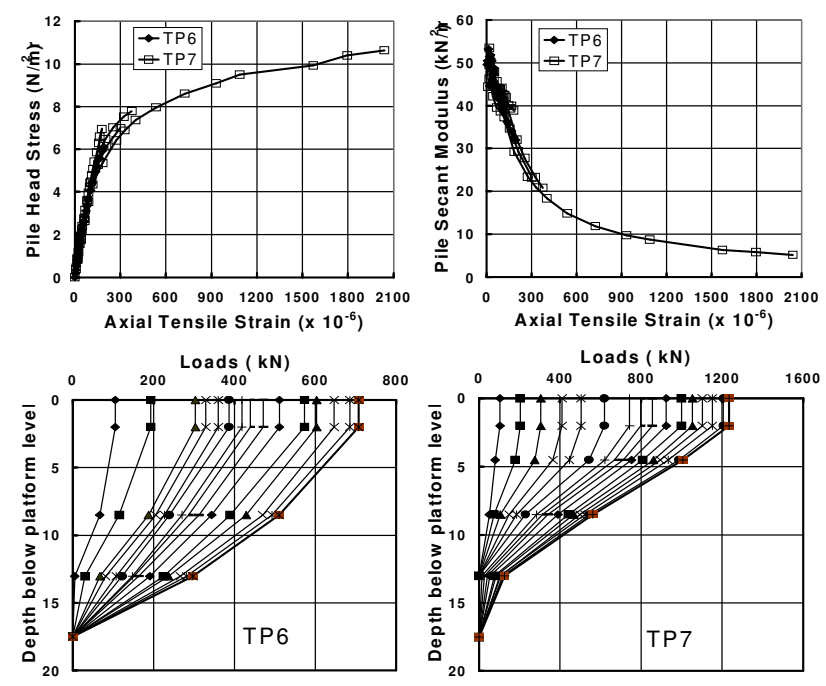

Fig.15: Tensile stress-strain curves, modulus-strain curves and load distribution curves for TP6 and TP7

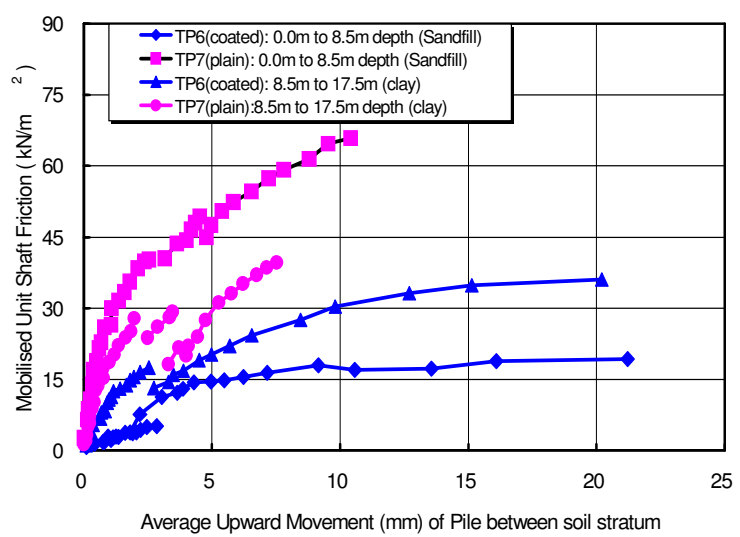

Fig. 16: Mobilized unit shaft friction characteristic, TP6 and TP7 test results acquired from measurement using global strain extensometer technology at Jimah site, Malaysia

and strains at various levels down the pile shaft to be accurately determined, thus permitting a significantly improved means for the acquisition of load transfer data.

The technology not only enables ease of the assessment of modulus-strain relationship and load transfer study (Fig. 15), it also significantly improves the reliability of the measurement of movement of pile between deeper soil stratums, as illustrated in the characteristic curves of mobilized unit shaft friction (Fig. 16).

\section{CONCLUSIONS}

Considering the inherent shortcomings of conventional and approximate instrumentation method for spun piles, the global strain extensometer technology appeared to be a more superior and logical evolution due to its revolutionary difference in the methodology approach, from conventional sacrificial cast-in method to a new retrievable post-install nature. Field tests using this technology on both driven and jacked-in spun piles showed high quality, reliable and consistent data, clearly far exceeding the capability of both conventional and approximate methods.

The advanced features and novel nature of the global strain extensometer technology also made it an improved alternative of instrumentation approach to the following research areas, where it could be too cumbersome and sometimes economically not viable if using conventional and approximate methods: 
- Fully instrumented piles for long term load transfer characteristic study, including both positive and negative skin friction development with time;

- Study of locked-in stresses in piles due to handling and installation process, particular suitable for jacked-in piles;

- Fully instrumented piles for study of influence due to installation process of adjacent piles;

- Study of pile joints performance under loadings;

- Mass implementation of spun piles instrumentation in fast- track projects.

\section{REFERENCES}

1. Chan, S.F. \& Lee, C.S.P. 1990. The design of foundations for Suntec City, Singapore, Proceedings of Conference on Deep Foundation Practice, Singapore.
2. Chan, S.F. 2004. Special lecture, design and construction of Foundations for Suntec City, Singapore, Proceedings of the Malaysian Geotechnical Conference, Malaysia, pp 21-43.

3. Fleming, K. 1996. Talking Point: Ken Fleming assesses the present major issues in the pile testing industry. Page 3, Ground Engineering October 1996.

4. Fleming, K. 1992. A new method for single pile settlement prediction and analysis. Geotechnique 42, No.3, 411-425. 